\title{
American Journal of
}

\section{Health, Medicine and Nursing Practice}

(AJHMN)

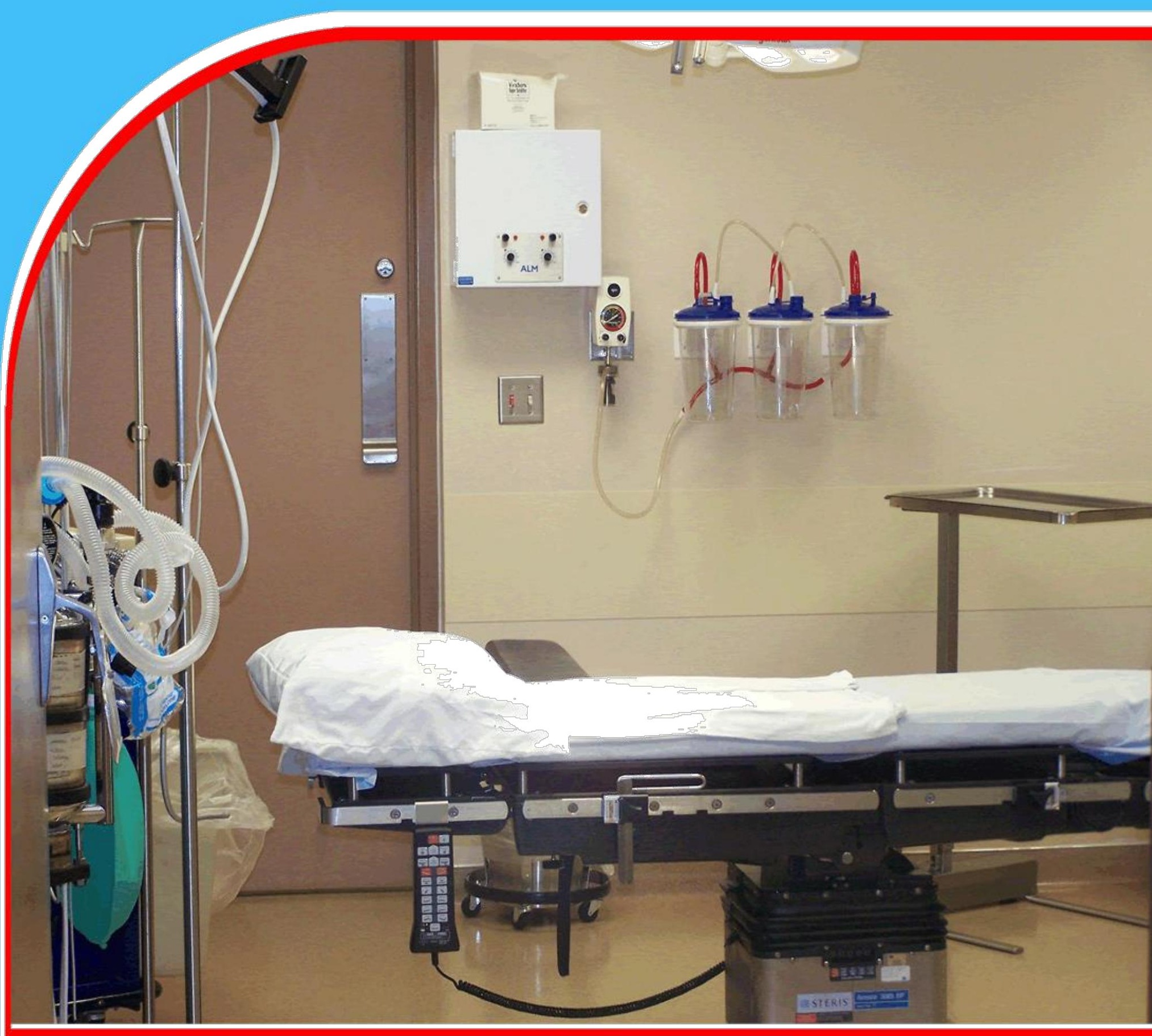

ASSESSING FACTORS ASSOCIATED WITH OBSERVED LEVELS

OF ADHERENCE TO ANTIRABIES PEP VACCINE AMONG

ANIMAL BITE VICTIMS IN MACHAKOS LEVEL FIVE HOSPITAL

Alice N. Gichohi, Dr. Yeri Kombe, Dr.Peter Mwaniki Dr.Joseph Mutahi and Anne G. Macharia 


\title{
ASSESSING FACTORS ASSOCIATED WITH OBSERVED LEVELS OF ADHERENCE TO ANTIRABIES PEP VACCINE AMONG ANIMAL BITE VICTIMS IN MACHAKOS LEVEL FIVE HOSPITAL
}

\author{
${ }^{1 *}$ Alice N. Gichohi \\ ${ }^{1 *}$ Post graduate student \\ Jomo Kenyatta University of Agriculture and Technology (JKUAT), Kenya \\ *Corresponding Author's Email: alice_shecan@yahoo.com \\ ${ }^{2}$ Dr. Yeri Kombe \\ Lecturer, Kenya Medical Research Institute \\ ${ }^{3}$ Dr.Peter Mwaniki \\ Lecturer, Jomo Kenyatta University of Agriculture and Technology (JKUAT), Kenya \\ ${ }^{4}$ Dr.Joseph Mutahi \\ Lecturer, Kenya Medical Research Institute (KEMRI) \\ ${ }^{5}$ Anne G. Macharia \\ Lecturer, Epidemiologist St. Lukes Nurse Training College
}

\begin{abstract}
Purpose: The purpose of this study was to determine factors associated with observed levels of adherence to ant rabies PEP vaccine among animal bite victims in Machakos level five hospital.

Methodology: The study used Cross sectional study design. It utilized both qualitative and quantitative methods. Data was collected by use of semi-structured questionnaires, physical examination sheet and key informant interview. The study population was victims of animal bites who revisited the health facility for the scheduled PEP vaccine. Random Sampling was used to select the revisiting animal bite victims until a sample size of 68 was achieved. Purposive sampling was used to select health care workers directly involved in management of animal bite victims until a sample size of three was achieved. Quantitative data was analyzed using SPSS version 20 and excel computer programs. Qualitative data was analyzed by content analysis. Binary logistic regression and multivariate regression was done.

Results: The study findings established that knowledge of rabies significantly affects the level of adherence to antirabies PEP vaccine. At least $48.50 \%$ of the respondents admitted that they have no knowledge of rabies and $75 \%$ had no knowledge of prevention of rabies. The study also found out that affordability of the cost of PEP vaccine is statistically associated with adherence to anti-rabies PEP vaccination.

Unique contribution to theory, practice and policy: The study concluded that: the level of adherence and the overall awareness not only of anti-rabies PEP vaccine, the follow-up of victims to check on the completion of the anti-rabies PEP vaccine schedule but also the management of wounds before visiting health facilities among animal bite victims in MKS L5 Hospital is low, thus a major public health concern both to the community and the county government.
\end{abstract}

Keywords: anti-rabies, pep vaccine, accessibility, adherence, awareness, machakos level 5 hospital 


\subsection{INTRODUCTION}

\subsection{Background of the Study}

Rabies is a viral disease that affects the central nervous system. It affects both animals (animal rabies) and man (human rabies) (Cohen \& Powderly, 2004). Rabies virus has its reservoir in dogs, cats and bats with dogs being the major reservoir and hence source of the vast majority human rabies deaths (Willoughby et al., 2005). According to MOPHS (2011) thirty percent of rabies cases are paralytic. The MOPHS (2011) report also state that human rabies is present in all continents except Antarctica but $95 \%$ of human deaths occur in Asia and Africa. It occurs in more than 150 countries and more than 55,000 people die of human rabies each year in Africa and Asia. Africa accounts for 24,000 deaths annually. Rabies control in Kenya has been hampered by the high cost and scarce supplies of high quality vaccines. In Machakos County, despite the domestication of dogs, human rabies has been endemic for over 40 years with stray dogs increasing in number and is a health hazard to the human population. This is worsened by the ignorance portrayed by the dog owners regarding the need and value to vaccinate dogs and other pets. There is also a great drop out of the bitten victims from the post exposure prophylaxis and a poor follow up of such victims by the relevant departments hence increasing the risk of acquiring the disease.

According to MOPHS (2012), the total number of human rabies deaths in Kenya confirmed by laboratory tests was 2 in 2010, 1 in 2011 and 1 in 2012. The total number of human rabies deaths diagnosed on clinical grounds only in 2010, 2011 and 2012 were not recorded. The total number of people bitten by dogs recorded as animal bites was 38,944 in 2010: 133,150 in 2011 and 146,362 in 2012. Animal rabies has been widespread in the country over the last ten years. To date, all the eight provinces have at least had rabies. Generally, the number of districts with positive cases has ranged from seventeen to twenty nine. Eastern, Rift Valley, Central and Nairobi Provinces contributed slightly over ninety five percent of total rabies cases over 1983 - 1992 periods. The highest Incidence was in Machakos in Eastern, followed by Nairobi, then Nakuru in Rift Valley, Nyeri and Kiambu in Central, and, Kericho in Rift Valley in that order, contributing nearly seventy two percent of the outbreaks. There has been no laboratory confirmed rabies recorded in Garissa and Mandera in North Eastern, and, Lamu and Tana River in Coast Provinces (Dept. of Veterinary Services Kabete., 1994). Surveillance studies on the disease according to Kitala et al. (1994), during the period 19811990 in Machakos County, indicates that the study had 8027 people bitten by dogs and 4947 of them received PEP and 22 died of rabies. 505 confirmed cases of animal rabies were also reported by the Machakos district veterinary department during the same period. This is an indication of the situation in the district and not a precision since most of the cases are unreported. It also demonstrated the central role played by dogs in maintenance and transmission of the disease in the county.92\% of rabid suspect animals and $81 \%$ confirmed animals were dogs. Also, 97\% of the human animal bite cases were due to dogs. Therefore the high incidence of rabies in the county is due to a high dog density and minimal dog control which have a low vaccination rate Kitala et al. (1994),

\subsection{Problem Statement}

According to Si H et al. (1990-2007) the cause of increasing human rabies incidence globally is inadequate vaccine doses, reduced vaccine potency due to improper storage and the site and severity of the wound. The public health sector therefore advocates for health education to the general public and health care providers as well as implementing dog immunization due to the expanding dog population in various countries. In Kenya, legislation exists to ensure adequate control of rabies. However, in most cases, we operate under significant 
financial constraints leading to shortages of vaccines and insufficient logistical support for rabies control. The main factor limiting the efficacy of human rabies control is our inability to fully vaccinate all animal bite victims and the lack of existing practical follow up strategies reflected in the existing $\mathrm{MOH}$ policies for them. This would ensure proper adherence to the full anti-rabies regimen. In addition, all the vaccine used in the country is imported. The kind of funding necessary to mount and sustain PEP schedule becomes colossal and unaffordable through the government's normal expenditure allocations. The quantity of antirabies PEP vaccine supplied to the health facilities is therefore insufficient to meet the increasing demand of animal bite victims. Animal bite victims are hence left at a crossroad subjecting them to prolonged suffering and pain or purchase the vaccine at an exorbitant price (MOPHS, 2012).

\subsection{Research Objective}

To determine the level of awareness to antirabies PEP vaccine among animal bite victims in MKS L5 Hospital.

To determine factors associated with adherence to anti-rabies PEP vaccine among animal bite victims in MKS L5 Hospital.

To establish the proportion of animal bite victims that was followed up for antirabies PEP vaccine in MKS L5 Hospital.

\subsection{LITERATURE REVIEW}

\subsection{Empirical Review}

Animal bite wounds from rabies suspects are classified into three categories and this determines their management. The first category refers to victims of touch or licks on intact skin who are hence not eligible for PEP. The second category refers to victims of minor scratches, abrasions without bleeding who are hence eligible for PEP. Category three refers to victims of single or multiple transdermal bites, licks on broken skin and contamination of mucous membranes with saliva from licks. These victims require immediate vaccination of rabies immunoglobulin (Razzouk et al., 2010).

Assessment of risk is done depending on whether the biting animal is wild or domesticated, has abnormal behavior or not, the bite was unprovoked and also whether the animal had been vaccinated. The consequences of dog bites to humans are many. The most common is the direct physical injury. Sometimes the injury may cause permanent disfigurement of the victims requiring reconstructive surgery, psychological trauma and posttraumatic stress where as others can be fatal (Hunter \& Brown, 2007).

A study carried out in the United States on rabies post exposure prophylaxis revealed that there are relatively significant rate of errors in its use. It also identified that it is only through effective dealing with domestic animals that are linked to animal bites appeared to be the most appropriate way of reducing the PEP cost (Hunter \& Brown, 2007). There are disparities in the accessibility and affordability of PEP treatment resulting in a skewed distribution of the disease burden across society, with the major impact falling on those living in poor rural communities, in particular children (Knobel et al., 2005).

The human population boom in Africa appears to correlate well with the increase in the number of domestic dogs. Nevertheless, by conservative estimates, the prevalence of human rabies is considered to be under-reported. The underreporting is largely attributed to poor surveillance systems and people's tendency not to report human and animal cases of rabies. Therefore, there has been poor planning resulting in poor availability and inappropriate administration of post-exposure prophylaxis as well as delays in administration. Although not as frequent as the inability to afford treatment, such scenarios have built a false picture of health facilities, as well as poor compliance with PEP regimen [18]. Other reasons given for 
not reporting, completing or adhering to PEP include poor awareness about the danger of the disease, small size of the injury, reluctance of the dog owner to pay for treatment costs, and not being advised to take PEP (WHO, 2010).

According to Wilde et al. (2003), rabies is a neglected disease in many developing countries though the preventive tools are known. There is need for more funding, for study of dog population-control measures, and for sustainable canine immunization. Safe and effective tissue-culture rabies vaccines and human and equine rabies immunoglobulin (HRIG and ERIG) are not readily available in many regions where rabies is endemic. This and the continuing presence and spread of rabies have increased the risk for travelers, who cannot rely on being able to receive optimal post exposure treatment in many parts of the world. Alternatives to HRIG or ERIG are not available.

A study done by virologists from Africa, USA and France reported that the rabies virus circulating in western and central Africa is from a common ancestor introduced into the continent about 200 years ago probably by European colonialists. Within this common species there are subspecies at each country level which only circulate between localities. Their study analyses showed that there were two types of the rabies virus in Africa namely Africa 1 and Africa 2 with different geographical distribution. Therefore, by identifying the species of the virus that is most prevalent and how it spreads through Africa, it will be possible for African countries to control the disease by use of the appropriate vaccine. This implies that collaboration amongst neighbouring countries is a progressive strategy to eliminate rabies from sub-Saharan Africa (WHO, 2010).

\subsection{RESEARCH METHODOLOGY}

The study was carried out in Machakos level five hospital (MKS L5) at the division of vaccine and immunization where anti-rabies PEP is administered. MKS L5 is in the lower zone of former Eastern province and a referral hospital to all those health facilities below this tier in the Kenyan health care system. It serves approximately 200,000 patients annually (MOPHS, 2012). The study was carried out in the year 2015. The study used Cross sectional study design. The study population was victims of animal bites who revisited the health facility for the scheduled PEP vaccine. Sample size was determined using by Fisher formula. Random Sampling was used to select the revisiting animal bite victims until a sample size of 68 was achieved. Purposive sampling was used to select health care workers directly involved in management of animal bite victims until a sample size of three was achieved. The study used both qualitative and quantitative primary data. The animal bite victims who consented or assented to take part in the study and all victims of suspected rabid bites who were in category two to category five of adherence at MKS L5 hospital were included in the study. New animal bite victims to the facility seeking antirabies PEP vaccine, animal bite victims with bites by animals which don't transmit rabies (reptiles, insects), animal bite victims who were in severe pain and needed emergency care, Minors below 18 years who were not accompanied by their parents or guardians for consent to the study and animal bite victims who did not consent or assent to take part in the study were not included in the study. The study used qualitative and quantitative primary data. Quantitative data was collected using semi-structured questionnaires administered to the animal bite victims. Qualitative data was collected using interview guide questions. A physical examination was also done on the animal bite victim so as to determine the extent and nature of the wound. This was scored and reported as demonstrated in the attached physical examination sheet. Data from the questionnaires and physical examination sheet was analysed using SPSS version 20.0 statistical software. The study used Univariate analysis to obtain descriptive statistics such 
measures of central tendency like mean, standard deviation and range for continuous variables. Multivariate Analysis was performed using Binary logistic regression where backward conditional method was specified in order to adjust for confounding and/or effect modification. Adjusted odds Ratios (AOR) together with their respective 95\% Confidence Interval (CI) were used to estimate the strength of association between the retained independent predictors and dependent variable. Qualitative data was analysed using content analysis.

\subsection{RESULTS AND DISCUSSIONS}

\subsection{Demographics}

A total of 68 respondents were enrolled into this study and males were 39(57\%) while females were $29(43 \%)$ as shown in figure 1.

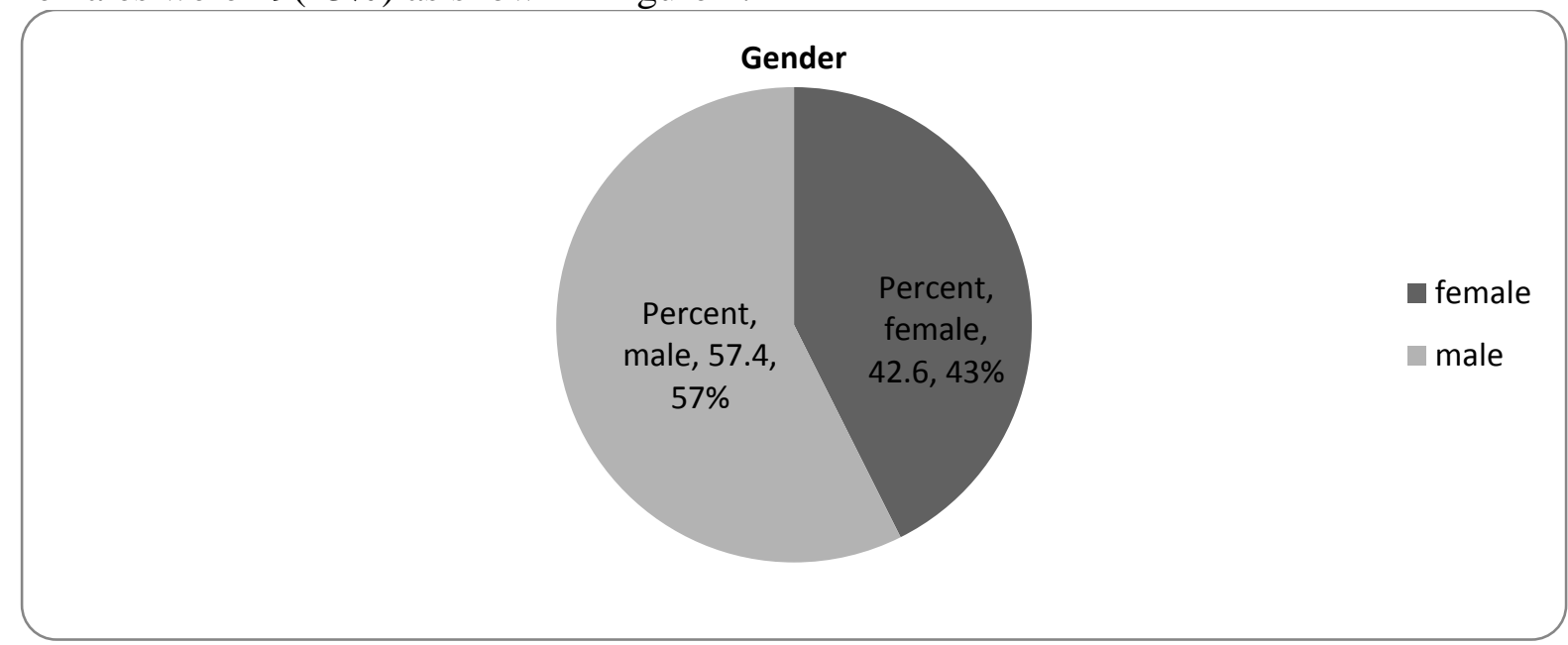

\section{Figure 1: Gender}

The age of the participants ranged up to 59 years with a mean age of 38.5 years. Under 18 years old respondents who were accompanied by their parents who consented to the study were $29.4 \%$. Respondents in the age group $18-28$ were $22.7 \%$, those in $29-38$ categories were $23 \%$ while those in age groups $39-48$ were $15.3 \%$ and a further $9.6 \%$ were in the $49-60$ category as shown in figure 2 .

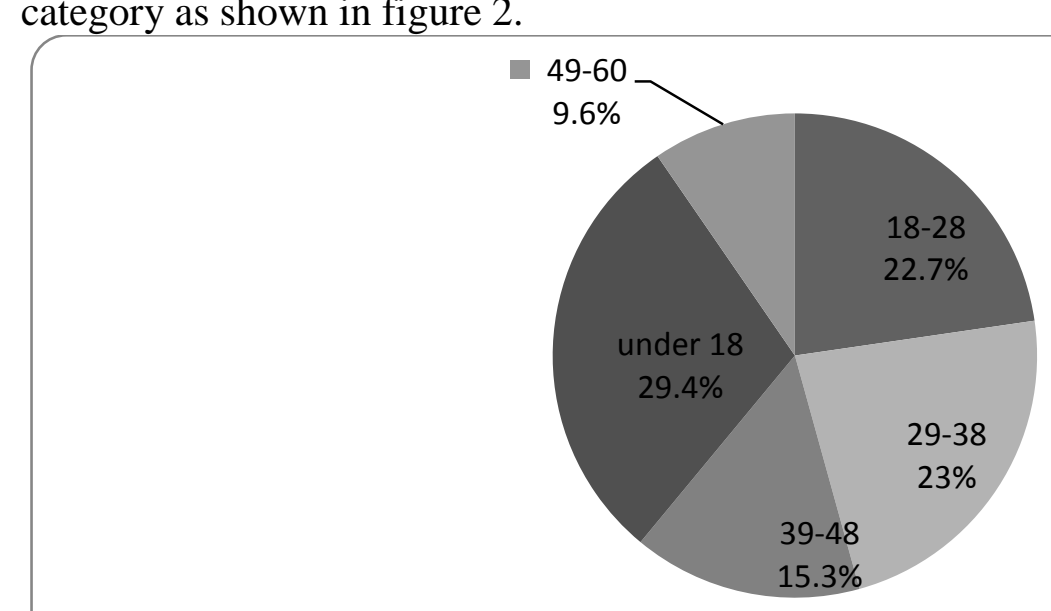




\section{Figure 2: Age}

\subsection{Level of awareness to anti-rabies pep}

The level of awareness to anti-rabies PEP vaccine among animal bite victims in MKS L5 Hospital was found to be $78 \%$ low level of awareness which represents 53 out of 68 respondents while those with high level of awareness were $22 \%$ as shown in figure 3 .

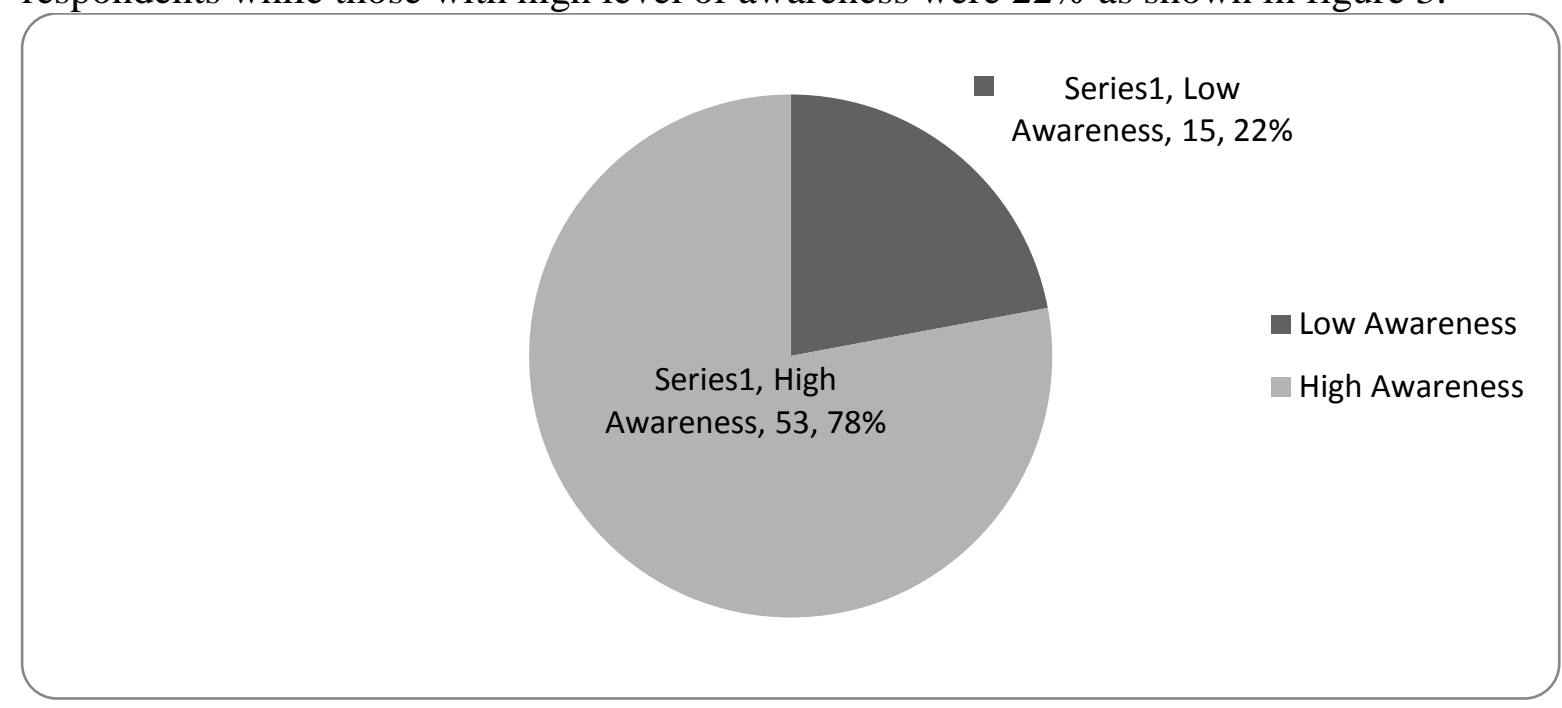

Figure 3: Level of Awareness

\subsection{Factors associated with adherence to anti rabies PEP Vaccine}

\subsubsection{Assessment of awareness}

At least $48.50 \%$ of the respondents admitted to have no knowledge of rabies and $75 \%$ had no knowledge of prevention of rabies.29.40\% of the respondents said that vaccination of animal is the only preventive measure of rabies while majority (30.90\%) said that vaccination of the animal bite victim is the only preventive measure. However, at least $20.60 \%$ say that early treatment of animal bite is the only preventive measure of rabies and $19.10 \%$ said that both Vaccination of animal, vaccination of animal bite victim and early treatment of animal bites are the preventive measures of rabies. On management of the wound before visiting a health center, at least $47.10 \%$ of the respondents agreed that they clean the wound. Majority of the respondents $(36.80 \%)$ seek medical care within a day of being bitten while at least $27.90 \%$ seek medical attention immediately they are bitten. The respondents who know whether the animal that bites them is vaccinated are $50 \%$ while $19.10 \%$ have no knowledge of the same. Majority of the respondents (41) (60.3\%) said that they were bitten by a dog, (22) $32.35 \%$ said they were bitten by a cat, and only (5)7.4\% by a monkey.

Tabulations of the findings from the physical examination sheet represented in Table 2 showed that majority of the respondents (40) (60\%) were bitten on the leg, (21) $31 \%$ on the buttocks and (7) $9 \%$ on the hand of which (59) $87 \%$ had not healed and (9) were healed. The physical examination sheet for bite examination also showed that Category I (Low risk) bite were (9) (13\%), Category II (Moderate risk) (42) (62.30\%) and Category III (high risk) were (17) $24.70 \%$. 
American Journal of Health, Medicine and Nursing Practice

ISSN xxxx-Xxxx (Paper) ISSN XXXX-XXX (Online)

Vol.1, Issue 1 No.1, pp 1-15, 2017

www.ajpojournals.org

Table 1: Assessment of Awareness

\begin{tabular}{|l|l|l|l|}
\hline Statement & Response & $\begin{array}{l}\text { Cou } \\
\text { nt }\end{array}$ & $\begin{array}{l}\text { Percent } \\
\text { age }\end{array}$ \\
\hline Knowledge of rabies & No & 33 & $48.50 \%$ \\
\hline Knowledge of prevention of rabies & Yes & 35 & $51.50 \%$ \\
\hline & No & 51 & $75.00 \%$ \\
\hline Knowledge of Preventive measure of rabies & Yes & 17 & $25.00 \%$ \\
\hline & $\begin{array}{l}\text { Vaccination of animal } \\
\text { bite viction of animal }\end{array}$ & 20 & $29.40 \%$ \\
\hline $\begin{array}{l}\text { Early treatment of } \\
\text { animal bites }\end{array}$ & 21 & $30.90 \%$ \\
\hline $\begin{array}{l}\text { Cleaning the wound immediately before } \\
\text { visiting a health center. }\end{array}$ & No & 14 & $20.60 \%$ \\
\hline & Yes above & 13 & $19.10 \%$ \\
\hline $\begin{array}{l}\text { Time taken before seeking medical care after } \\
\text { the bite }\end{array}$ & Immediately & 36 & $52.90 \%$ \\
\hline & Within a day & 32 & $47.10 \%$ \\
\hline & After a day & 19 & $27.90 \%$ \\
\hline $\begin{array}{l}\text { Knowledge of whether the animal was } \\
\text { vaccinated }\end{array}$ & No & 25 & $36.80 \%$ \\
\hline & Yes & 13 & $35.30 \%$ \\
\hline & Don't Know & 21 & 34 \\
\hline
\end{tabular}

\subsubsection{Assessment of adherence factors}

Results in table 3 shows that $50.0 \%$ of the respondents said that the distance to health facility was far and only $16.20 \%$ said it is close. The main means of transport to the health facilities is vehicle $(36.80 \%)$ and motorcycle $(32.40 \%)$ and $30.90 \%$ walk to the health facility. Majority of the respondents $(57.40 \%)$ buy the anti-rabies PEP vaccine and $69.10 \%$ of them believe that the cost is not affordable. The results also indicate that majority of the respondents $(57.40 \%)$ wait for over 30 minutes at the health facility before being attended to. Those that have plans to complete the scheduled vaccination are $60.30 \%$. 
American Journal of Health, Medicine and Nursing Practice

ISSN xxxx-Xxxx (Paper) ISSN XXXX-XXX (Online)

Vol.1, Issue 1 No.1, pp 1-15, 2017

$\underline{\text { www.ajpojournals.org }}$

Table 2: Assessment of adherence factors

\begin{tabular}{|l|l|l|l|}
\hline Statement & Response & $\begin{array}{l}\text { Cou } \\
\text { nt }\end{array}$ & $\begin{array}{l}\text { Percenta } \\
\text { ge }\end{array}$ \\
\hline Distance of the health facility & Very far & 23 & $33.80 \%$ \\
\hline & Far & 34 & $\mathbf{5 0 . 0 0 \%}$ \\
\hline Means of transport to the health facility & Close & 11 & $\mathbf{1 6 . 2 0 \%}$ \\
\hline & vehicle & $\mathbf{2 5}$ & $\mathbf{3 6 . 8 0 \%}$ \\
\hline & Motorcycle & $\mathbf{2 2}$ & $\mathbf{3 2 . 4 0 \%}$ \\
\hline $\begin{array}{l}\text { Duration of waiting at the health facility before } \\
\text { being attended to. }\end{array}$ & $\begin{array}{l}\text { Walking } \\
\text { 30mins }\end{array}$ & $\mathbf{2 1}$ & $\mathbf{3 0 . 9 0 \%}$ \\
\hline & $\begin{array}{l}\text { 30mins } \\
\text { 1hour }\end{array}$ & $\mathbf{2 9}$ & $\mathbf{4 2 . 6 0 \%}$ \\
\hline to & 39 & $\mathbf{5 7 . 4 0 \%}$ \\
\hline Frew vaccine was acquired & Bought & $\mathbf{2 9}$ & $\mathbf{4 2 . 6 0 \%}$ \\
\hline Affordability of the cost of PEP Vaccine & $\begin{array}{l}\text { Not } \\
\text { Affordable }\end{array}$ & $\mathbf{4 7}$ & $\mathbf{5 7 . 4 0 \%}$ \\
\hline & Affordable & $\mathbf{2 1}$ & $\mathbf{3 0 . 9 0 \%}$ \\
\hline Plans to complete scheduled vaccination & No & 27 & $\mathbf{3 9 . 7 0 \%}$ \\
\hline & Yes & $\mathbf{4 1}$ & $\mathbf{6 0 . 3 0 \%}$ \\
\hline
\end{tabular}

\subsubsection{Follow up}

The results in Table 4 indicate that once attended to, only $4.4 \%$ of the respondents said that the health workers get in contact with them to check on completion of the schedule. Majority (95.6\%) of the respondents reported that no healthcare worker gets in contact with them as a reminder of the next vaccine.

Table 3: Follow up

\begin{tabular}{|l|l|l|l|}
\hline Statement & $\begin{array}{l}\text { Respon } \\
\text { se }\end{array}$ & $\begin{array}{l}\text { Cou } \\
\text { nt }\end{array}$ & $\begin{array}{l}\text { Percenta } \\
\text { ge }\end{array}$ \\
\hline $\begin{array}{l}\text { Did healthcare worker get in contact as a reminder of next } \\
\text { vaccines }\end{array}$ & No & 3 & $4.4 \%$ \\
\hline & Yes & 65 & $95.6 \%$ \\
\hline
\end{tabular}

\subsection{Inferential Statistics}

4.4.1 Bivariate analysis of factors associated with adherence to anti-rabies PEP vaccine

Only three variables were found to be significantly associated with adherence to anti-rabies PEP vaccination. Knowledge about rabies was statistically associated with adherence to antirabies PEP vaccination. The odds of adherence to anti-rabies PEP vaccination was 4.412 times higher for respondents with knowledge about rabies as compared to respondents with no knowledge about rabies( $\mathrm{OR}=4.412 ; \mathrm{p}=0.036$ ). Results also revealed that another variable which is significantly associated with adherence to anti-rabies PEP vaccination is the distance of the health facility being far. The odds of adherence to anti-rabies PEP vaccination was 7.41 times higher if the distance to the health facility is far as compared to if the distance is very far.( $\mathrm{OR}=7.41 ; \mathrm{p}=0.006)$. Affordability of the cost of PEP vaccine is statistically associated with adherence to anti-rabies PEP vaccination. With affordable costs, the odds of adherence to anti-rabies PEP vaccination are 0.395 times higher as compared to nonaffordable costs. $(\mathrm{OR}=0.395 ; \mathrm{p}=0.033)$. 
Table 4: Bivariate Analysis

\begin{tabular}{|l|l|l|l|l|}
\hline Variable & $\begin{array}{l}\text { Beta } \\
\text { Coefficient }\end{array}$ & $\begin{array}{l}\text { Odds } \\
\text { Ratio }\end{array}$ & Df & P Value \\
\hline Knowledge of rabies & 2.998 & $\mathbf{4 . 4 1 2}$ & 1 & $\mathbf{0 . 0 3 6}$ \\
\hline $\begin{array}{l}\text { How far is the health facility (very far- } \\
\text { Reference) }\end{array}$ & & 7.41 & 2 & 0.025 \\
\hline How far is the health facility(Far) & 4.175 & $\mathbf{7 . 4 1}$ & 1 & $\mathbf{0 . 0 0 6}$ \\
\hline How far is the health facility(Close) & -12.236 & 0 & 1 & 0.999 \\
\hline Is the cost affordable(Yes) & 0.748 & $\mathbf{0 . 3 9 5}$ & 1 & $\mathbf{0 . 0 3 3}$ \\
\hline Age Group & 2.158 & 3.031 & 1 & 0.082 \\
\hline Constant & -15.08 & 6.473 & 1 & 0.011 \\
\hline
\end{tabular}

4.4.2 Multivariate analysis of factors associated with adherence to anti-rabies PEP vaccine

A multivariate logistic regression was used to model relationship between all significant independent constructs found in binary stage and adherence to anti-rabies PEP vaccination. Results revealed that having knowledge about rabies is significantly associated with adherence to anti-rabies PEP vaccination. The odds of adherence to anti-rabies PEP vaccination was 10.58 times higher for respondents with knowledge about rabies as compared to respondents with no knowledge about rabies $(\mathrm{OR}=10.58 ; \mathrm{p}=0.001)$. Distance to the health facility is also significantly associated with adherence to anti-rabies PEP vaccination. If the distance is far, the odds of adherence to anti-rabies PEP vaccination is 6.165 times higher as compared to when the distance is very far. $(\mathrm{OR}=6.165 ; \mathrm{p}=0.013)$.

Table 5: Multivariate Analysis

\begin{tabular}{|l|l|l|l|l|}
\hline Variables & B & $\begin{array}{l}\text { Odds } \\
\text { ratio }\end{array}$ & df & P value \\
\hline Knowledge of rabies & 3.772 & $\mathbf{1 0 . 5 8}$ & 1 & $\mathbf{0 . 0 0 1}$ \\
\hline $\begin{array}{l}\text { How far is the health facility(Very far- } \\
\text { Reference) }\end{array}$ & & 6.165 & 2 & 0.046 \\
\hline How far is the health facility(Far) & 2.343 & $\mathbf{6 . 1 6 5}$ & 1 & $\mathbf{0 . 0 1 3}$ \\
\hline How far is the health facility(Close) & -18.953 & 0 & 1 & 0.999 \\
\hline Is the cost affordable(Yes) & 0.735 & 0.704 & 1 & 0.401 \\
\hline Constant & -5.556 & 14.942 & 1 & 0 \\
\hline
\end{tabular}

\subsection{DISCUSSION CONCLUSIONS AND RECOMMENDATIONS}

\subsection{Discussion}

The age of the participants ranged up to 59 years with a mean age of 38.5 years. Under 18 years old respondents who were accompanied by their parents who consented to the study were $29.4 \%$. Respondents in the age group $18-28$ were $22.7 \%$, those in $29-38$ categories were $23 \%$ while those in age groups $39-48$ were $15.3 \%$ and a further $9.6 \%$ were in the $49-60$ category. The fact that more male are affected can be attributed to the fact that more male spend time in the field herding cattle and cultivating hence a big encounter with animals as compared to ladies. Under 18 years old respondents were also most affected due to the fact that children are more playful with pets especially dogs than adults.

The study sought to determine the level of awareness to antirabies PEP vaccine among animal bite victims in MKS L5 Hospital. The level of awareness to anti-rabies PEP vaccine among animal bite victims in MKS L5 Hospital was found to be low. Those respondents with low awareness were $79 \%$ representing 53 out of 68 respondents while those with high 
awareness were $21 \%$. Low awareness as presented by the findings can be attributed to low level of education and high level of illiteracy. Alexis and Kiefer, (2007) conducted a study on Social and Cultural factors related to health in South America and found out that, social factors such as education and literacy influence awareness and health outcomes. Abubakar et al. (2013) states that some of the Kenya Health Policy 2014-2015 objectives require the county governments to promote democracy and accountability in the delivery of health care . It is meant to further foster a flawless service delivery during and after the transition period, facilitate powers of independence to the citizens, and improve their participation in decision-making matters dealing with their health. The county government is also required to recognize the right of its county communities to manage their health affairs, protect, and promote the health interests of the special groups. This cannot be achieved if the health awareness is low. The county government should ensure that its community members are well informed on health matters to be able to promote their health interests and affairs well. The indication of low level of awareness might indicate that the county government of Machakos has not done enough to raise the level of awareness.

The study also sought to determine factors associated with adherence to anti-rabies PEP vaccine among animal bite victims in MKS L5 Hospital. Results indicated that among the factors associated with adherence to anti-rabies PEP vaccine is knowledge. It was found out that at least $48.50 \%$ of the respondents admitted to have no knowledge of rabies and $75 \%$ had no knowledge of prevention of rabies.29.40\% of the respondents said that vaccination of animal is the only preventive measure of rabies while majority $(30.90 \%)$ said that vaccination of the animal bite victim is the only preventive measure. $20.60 \%$ of the respondents say that early treatment of animal bite is the only preventive measure of rabies and $19.10 \%$ said that both vaccination of animal, vaccination of animal bite victim and early treatment of animal bites are the preventive measures of rabies. These results are consistent with the results reported by WHO (2010) which stated that among the reasons given for not reporting, completing or adhering to PEP include poor awareness about the danger of the disease and not being advised to take PEP. Results from the binary logistic regression showed that knowledge about rabies was statistically associated with adherence to anti-rabies PEP vaccination. The odds of adherence to anti-rabies PEP vaccination was 4.412 times higher for respondents with knowledge about rabies as compared to respondents with no knowledge about rabies( $\mathrm{OR}=4.412 ; \mathrm{p}=0.036$ ). Results on level of awareness on management of the wound before visiting a health centre revealed that at least $47.10 \%$ of the respondents agreed that they clean the wound. Majority of the respondents $(36.80 \%)$ seek medical care within a day of being bitten while at least $27.90 \%$ seek medical attention immediately they are bitten. The respondents who know whether the animal that bite them is vaccinated are $50 \%$ while $19.10 \%$ have no knowledge about the vaccination status of the animal that bite them. Lack of knowledge about anti rabies vaccine is linked to low awareness levels.

The results indicated that $50.0 \%$ of the respondents said that the distance to health facility was far and only $16.20 \%$ said it is close. The main means of transport to the health facilities is vehicle $(36.80 \%)$ and motorcycle $(32.40 \%)$ while $30.90 \%$ walk to the health facility Distance to the health facility was found to affect the level of adherence to anti-rabies PEP vaccine. Results indicated that distance to the health facility is significantly associated with adherence to anti-rabies PEP vaccination. The odds of adherence to anti-rabies PEP vaccination was 7.41 times higher if the distance to the health facility is far as compared to if the distance is very far.( $\mathrm{OR}=7.41 ; \mathrm{p}=0.006)$. Majority of the respondents $(57.40 \%)$ buy the anti-rabies PEP vaccine of which $69.10 \%$ believe that the cost is not affordable. The results 
also indicate that majority of the respondents $(57.40 \%)$ wait for over 30 minutes at the health facility before being attended to. Affordability of the cost of PEP vaccine is statistically associated with adherence to anti-rabies PEP vaccination. With affordable costs, the odds of adherence to anti-rabies PEP vaccination are 0.395 times higher as compared to nonaffordable costs $(\mathrm{OR}=0.395 ; \mathrm{p}=0.033)$. Affordability is a factor that affects adherence. The results found from this study are consistent with the results from a study by Knobel et al. (2005) which found out that there are disparities in the accessibility and affordability of PEP treatment resulting in a skewed distribution of the disease burden across society, with the major impact falling on those living in poor rural communities. Similar reports were reported by Abubakar et al. (2013) who stated that rabies control in Kenya has been hampered by the high cost and scarce supplies of high quality vaccines. The quantity of antirabies PEP vaccine supplied to the health facilities is insufficient to meet the increasing demand of animal bite victims. Clients are therefore forced to purchase the vaccine at an exorbitant price or miss out the PEP due to financial constraints.

Low adherence to anti rabies vaccine is supported by the culture of people in Machakos County. Lack of knowledge on bio medical treatments methods of victims of animal bites lead to low adherence to anti rabies vaccine dosage. Chibwana et al. (2009), state that cultural beliefs and practices may contribute to delay and low adherence to access of medical care. Abubakar et al. (2013) conducted a study on Socio-cultural determinants of health-seeking behaviour on the Kenyan coast. They state that many Africans in the rural setting would prefer to go to the hospital for care if the treatment was free. They prefer to spend money at a traditional healer than doing to hospital because they are not sure whether the hospital had the correct medicine/treatment. The cultural background of the people of Ukambani entails belief in the traditional medicine. Low adherence to anti rabies vaccine can be attributed to the preference of traditional medicine in the area. The claim is further supported by WHO (2002) report on traditional medicine which states that, at least $80 \%$ of people in Africa use traditional medicine at some point in their lives .Parents opt for one of the forms of treatment between traditional and bio medical and if this does not appear to be working, they opt for the other.

Affordability is another factor that leads to low adherence levels to the prescribed anti rabies vaccine. Affordability of vaccine might be attributed to high levels of poverty as Ukambani is a hardship area as rural residents of Machakos County report frequent crop failures and water shortages, and food relief has become a permanent feature of rural life (Porter in prep). The Machakos District was a net importer of maize for 14 of the years between 1942 and 1962 for which data are available, and for 8 of the years from 1974 to 1985. The ever present need for food relief has been previously attributed to overpopulation and environmental degradation, to colonization and development, or to insufficient development. These are indicators of poverty in the county. The fact that people are poor means that they cannot afford to complete the prescribed dosage on treatment of rabies hence having low adherence to the schedule. Preference is given to basic needs first. The poverty aspect is supported by a World Bank report (2014) which in the comparison of South Eastern counties poverty and wealth levels placed Machakos County with poverty level of 59.6, Kitui County 63.1 and Makueni county 64.1. Even though Machakos has least level of poverty among the three, it is far poorer as compared to the national level of 45.9. This can best be used to explain the affordability factor as one of the main factors hindering adherence to the uptake schedule of the anti rabies vaccine. 
The study also sought to establish the proportion of animal bite victims that was followed up for anti-rabies PEP vaccine in MKS L5 Hospital. The results revealed that once attended to, only $4.4 \%$ of the respondents said that the health workers get in contact with them to check on completion of the schedule. Majority (95.6\%) of the respondents reported that no healthcare worker gets in contact with them as a reminder of the next vaccine. The results are consistent with the results reported by a study conducted by Kitala et al. (1994) which reported that there is a great drop out of the bitten victims from the post exposure prophylaxis and a poor follow up of such victims by the relevant departments hence increasing the risk of acquiring the disease. Dillip et al. (2012) stated that inadequate financial resources and an under-resourced health care system contribute to delay in accessing medical facilities. These two cardinal factors only partially explain the observed trends in low uptake of optimal treatment patterns.

Only $6.9 \%$ of roads in Machakos County are paved and only $26.9 \%$ of the roads are considered to be good roads. That explains why accessibility is a problem. The terrain is rough and roads are not up to standards required. The bad roads hinder follow up activities. Machakos County government has an efficient ambulance service and mobile clinics that serves all the members of the county. This is in a bid to improve the follow up strategies in the county. The county government has initiated a program that aims at constructing dispensaries across the county in order to take the health care services closer to the people. That is a bid to reduce the distance when seeking medical attention. The county governor has also initiated an upgrade of Machakos Level Five Hospital by introducing new services such as renal dialysis services and a modern Intensive Care Unit. Machakos County government has invested over Kshs. 400 million in the health sector to upgrade and build new dispensaries and increase the awareness on health matters in the county (Kibui et al., 2015).

\subsection{Conclusions}

The study concluded that: the level of adherence and the overall awareness not only of antirabies PEP vaccine, the follow-up of victims to check on the completion of the anti-rabies PEP vaccine schedule but also the management of wounds before visiting health facilities among animal bite victims in MKS L5 Hospital is low, thus a major public health concern both to the community and the county government.

The study also concluded that there are few health centers in the County which can help in managing animal bite victims against rabies. This is because majority of the respondents admitted to covering a large distance before reaching Machakos L5 hospital. Since the findings reveal that majority of the respondents wait for longer periods of time before being attended to, the study concludes that service provision at Machakos level5 hospital is poor. An emergency case of rabies needs a faster medication attention. The study also concluded that the cost of anti-rabies PEP is not affordable among the community members of Machakos County. Another conclusion from the study is that there is a low rate of rabies victim's follow-up to check on completion of the anti-rabies PEP vaccine schedule.

\subsection{Recommendations}

The study recommends that the government should put more resources into raising the awareness and knowledge on rabies and its prevention in Machakos County. Among the awareness campaigns, awareness on management of wound by the victims should be included.

The study also recommends that the County government should work together with the hospital management to come up with strategies which would lead to increased vaccination coverage of dogs to reduce rabies transmission among the susceptible animals and humans. 
Mass vaccination of dogs and widespread immunization of humans has significantly reduced the number of human deaths from rabies globally. This is because the study found out that most rabies is caused by dog bites.

The study also recommends that the County government and administration of Machakos level five Hospital should come up with strategies of giving preferential treatment to animal bite victims who cannot afford to purchase the required anti-rabies drug. This is because majority of the victims cannot afford the vaccine. The County government should increase the amount devoted to free prescription of the Vaccine and also subsidize the cost further more than the current subsidy.

The study also recommends that Machakos County government and Machakos level five hospital should reach an agreement to hire more community health workers who would help carry out with the follow up process on rabies victim's to make sure that the completion of the anti-rabies PEP vaccine schedule is done.

\section{REFERENCES}

Abubakar, A., Van Baar, A., Fischer, R., Bomu, G., Gona, J. K., Newton, C. R. (2013). Socio cultural determinants of health-seeking behaviour on the Kenyan coast: a qualitative study.

Alexis, A. \& Kiefer, C. (2007).Social and Cultural factors related to health. University of California, San Francisco.

Chibwana, A.I, Mathanga, D.P, Chinkhumba, J, Campbell, C.H. (2009). Socio-cultural predictors of health-seeking behaviour for febrile under-five children in MwanzaNeno district, Malawi. Malaria Journal 8: 219. doi: 10.1186/1475-2875-8-219

Cohen, J. \& Powderly W. G. (2004) Infectious diseases $2^{\text {nd }}$ edition, St Louis: Mosby

Dillip, A., Alba S, Mshana, C., Hetzel, M.W., Lengeler, C. (2012) Acceptability - a neglected dimension of access to health care: findings from a study on childhood convulsions in rural Tanzania. BMC Health Serv Res 12. doi: 10.1186/1472-6963-12113

Hunter, D.j., \& Brown, J. (2007). A review of health management research. European journal of public health 17 Suppl 1: 33-37.

Kibui, A. W., Mugo, R. K., Nyaga, G., Ngesu, L. M., Mwaniki, I. N., \& Bernard Mwaniki, M. A. (2015). Health policies in Kenya and the new constitution for vision 2030.

Kitala, P.M., McDermott, J.J., Kyule, M.N. And Matere, C.N. (1994). Investigation of rabies incidence and control by active surveillance in Machakos District, Kenya .Journal of veterinary research

Knobel, D.L. et al (2005). Re-evaluating the burden of rabies in Africa and Asia. Bulletin of WHO

MOPHS (2011). Home Management of Malaria in Malindi and Lamu Districts, Coast Province. Nairobi: Ministry of Public Health and Sanitation. 
MOPHS report. (2012) shortage on anti-rabies vaccine, Nairobi, Kenya

Razzouk, D., Sharan, P., Gallo C, Gureje, O., Lamberte, E.E, et al. (2010). Scarcity and inequity of mental health research resources in low-and-middle income countries: a global survey. Health policy: Amsterdam, Netherlands.

Si H et al. (1990-2007) Rabies trend in China and post-exposure prophylaxis in the Guangdong province. BMC Infect Dis 2008 Aug 21; 8:113.

WHO (2002) WHO Traditional Medicine Strategy 2002-2005. Geneva: WHO.

WHO weekly epidemiological record, (2010) rabies vaccines; WHO position paper vol.85; 309-320

Willoughby R. J, Tieves, K.S., Hoffman, G.M., Ghanayem, N.S., Amlie-Lefond, C.M., Chusid, M.J., Rupprecht, C.E. (2005).Survival after treatment of rabies with induction of coma. NEngl J Med. 